\title{
Long non-coding RNA Miat mediates cross-talk between the kidneys and hippocampus in the rat model of acute kidney injury
}

\author{
Maryam Malek ${ }^{1 *}$ (iD), Farnaz Mohammadtaheri ${ }^{2}$, Parvaneh Nikpour $^{3}$, Azar Baradaran $^{4}$ \\ 1. Department of Physiology, School of Medicine, Isfahan University of Medical Sciences, Isfahan, Iran \\ 2. Department of Genetics, Faculty of Basic Sciences, Shahrekord University, Shahrekord, Iran \\ 3. Department of Genetics and Molecular Biology, Faculty of Medicine, Isfahan University of Medical Sciences, Isfahan, Iran \\ 4. Department of Pathology, School of Medicine, Isfahan University of Medical Sciences, Isfahan, Iran
}

\begin{abstract}
Introduction: The role of long noncoding RNAs (IncRNAs) has been intensively studied in the development of several human diseases. Myocardial infarctionassociated transcript (Miat) is among the most abundant and highly conserved IncRNAs that exhibits deregulation in some critical diseases. However, it remains unclear whether Miat may also play a role in the pathogenesis of acute kidney injury $(\mathrm{AKI})$ and neurological consequences.
\end{abstract}

Methods: In the present study, the expression of IncRNA Miat was measured in the rat kidney and hippocampus tissues to assess if there is an association between the expression of it and AKI. AKI was induced by clamping the bilateral renal artery for $45 \mathrm{~min}$ and was confirmed 24 hours after reperfusion by biochemical markers and histopathological assessments in rat kidneys.

Results: We observed an increasing trend of Miat expression (256-fold) in the kidney as well as the hippocampus (2-fold) following AKI.

Conclusion: It appears that there is a relationship between the deregulation of the Miat expression and $\mathrm{AKI}$ and the hippocampal involvement, although more studies are needed to confirm the functional effect of this IncRNA in AKI.

\section{Keywords:}

Long non-coding RNA;

Miat;

Acute kidney injury;

Hippocampus

\section{* Corresponding author: Maryam Malek Email: malek.maryam@med.mui.ac.ir Tel: +98 (31) 37929187}

Received 27 March 2019; Received in revised form 24 August 2019; Accepted 24 August 2019

http://dx.doi.org/10.32598/ppj.24.1.10

\section{Introduction}

Acute kidney injury (AKI) is a complex disorder with high morbidity and mortality rate, especially when associated with multi-organ dysfunction syndrome in critically ill patients (Doi and Rabb, 2016). Renal ischemia/reperfusion, the most common cause of acute kidney injury, occurs in situations such as myocardial infarction, stroke, major surgeries and renal transplantation (Salvadori et al., 2015). AKI is not only locally limited to the kidney, but also affects remote organs such as the heart, lung, liver and brain that worsens outcomes (Shiao et al., 2015). The most important remote organic syndrome of acute or chronic renal failure is uremic encephalopathy, although the symptoms are more pronounced and 
progression is more rapid in the acute kidney injury than the chronic renal failure (De Deyn et al., 1992; Burn and Bates, 1998). Neurological manifestations of AKI vary from dizziness to delirium, memory disorders, seizures, coma and even death (Burn and Bates, 1998). The pathophysiology behind uremic encephalopathy is incompletely understood. Oxidative stress and systemic inflammatory reactions as well as blood-brain barrier disruption after AKI have been implicated in the pathogenesis of the brain hippocampus injury (Liu et al., 2008; Lu et al., 2015). Systemic cytokines mediate brain inflammation and hippocampal transcriptional dysregulation after renal ischemia/reperfusion (Chou et al., 2014). Long noncoding RNAs (IncRNAs) are a large and diverse class of non-protein coding transcripts which are longer than 200 nucleotides and function as transcriptional or post-transcriptional regulators of gene expression. The deregulation of IncRNAs has been recently documented in various human diseases including cancer (Nasrollahzadeh-Khakiani et al., 2017a; Nasrollahzadeh-Khakiani et al., 2017b), neurological disorders, inflammatory diseases and heart as well as kidney diseases (Niland et al., 2012; Fenoglio et al., 2013; Lorenzen and Thum, 2016). Myocardial infarction-associated transcript (Miat) also known as Gomafu in human or Rncr2 in mouse was originally identified as a IncRNA in 2000 (Ohnishi et al., 2000; Blackshaw et al., 2004; Ishii et al., 2006; Sone et al., 2007). Miat deregulation has been exhibited in various diseases such as myocardial infarction, microvascular dysfunction, ischemic stroke, diabetic retinopathy, diabetic nephropathy and mental disorders (Sun et al., 2018). However, it remains unclear whether Miat may also play a role in the pathogenesis of AKI. Therefore, in the present study, the expression of IncRNA Miat was measured in the rat kidney and hippocampus tissues to assess if there is an association between the expression of it and AKI.

\section{Materials and methods}

\section{Animals}

Sixteen male Wistar rats weighing 200 $\pm 20 \mathrm{~g}$ (4-6 months old) were randomly divided into two groups of eight animals each and housed in environmentally controlled animal room $\left(22-25^{\circ} \mathrm{C}\right.$; a light-dark cycle of 12:12h). Rodent chow and tap water were provided ad libitum throughout the acclimatization and study periods. Protocols were approved by the Animal Experimentation Ethics Committee of the Isfahan University of Medical Sciences (Ethical Code: IR.MUI.REC.1395.1.068).

\section{Induction of AKI}

Animals were randomly divided into two groups of eight rats: sham-operated control group and ischemia-reperfusion injury group as an AKI model. Rats were then anesthetized using intraperitoneal injection of xylazine $(10 \mathrm{mg} / \mathrm{kg})$ and ketamine hydrochloride $(90 \mathrm{mg} / \mathrm{kg})$. The kidneys were exposed through two small flank incisions. AKI was induced by bilateral renal pedicle clamping (45min) followed by releasing the clamps to revascularize. Occlusion was indicated visually by the change in the color of the kidney into a paler shade followed by a blush color when reperfusion occurred. Sham-operated control rats were undergoing the same surgical procedure except that the clamps were not applied. Then, the kidneys were returned to the abdomen, muscle layer and skin was closed with 3/0 polypropylene and 4/0 mononylon sutures, respectively and covered with antibiotic ointment after surgery.

\section{Samples collection}

Twenty-four hours after reperfusion, the awake rats were anesthetized and blood samples $(0.5 \mathrm{ml})$ were drawn directly from the heart. Blood samples were allowed to clot for $30 \mathrm{~min}$ at the room temperature before centrifugation, the sera were separated and stored at $-20^{\circ} \mathrm{C}$ until urea and creatinine were being assayed using an autoanalyzer. Rats were then sacrificed via injection of potassium chloride (10\% $\mathrm{KCl})$ into the heart. The right kidney and dissected hippocampus samples were immediately removed and frozen in the liquid nitrogen and the left kidney was fixed in $10 \%$ formalin for further histological analysis.

\section{Histology}

Paraffin-embedded sections from the formalin-fixed kidney tissues were sliced into $4 \mu \mathrm{m}$ thick sections and stained with hematoxylin and eosin. Acute tubular necrosis of kidneys was graded and judged on a scale of $0-4 \quad(0=$ normal kidney; $1=$ minimal damage $[<5 \%$ involvement of the cortex or outer medulla]; $2=$ mild damage [ $5-25 \%$ involvement of the cortex or outer medulla]; $3=$ moderate damage [25- 
Table 1: Sequences of primers utilized in this study

\begin{tabular}{lll}
\hline Primers & Primers sequences & Product length (bp) \\
\hline rMiat-F1 & TGATGTAATGGTGGCAGAGTG $(21 \mathrm{mer})$ & $188 \mathrm{bp}$ \\
rMiat-R1 & TCCATGAGGTCAGAATCCAAG $(21 \mathrm{mer})$ & \\
\hline rAct-F1 & GCCTTCCTTCCTGGGTATG $(19 \mathrm{mer})$ & $178 \mathrm{bp}$ \\
rAct-R1 & TAGGAGCCAGGGCAGTAATC $(20 \mathrm{mer})$ &
\end{tabular}
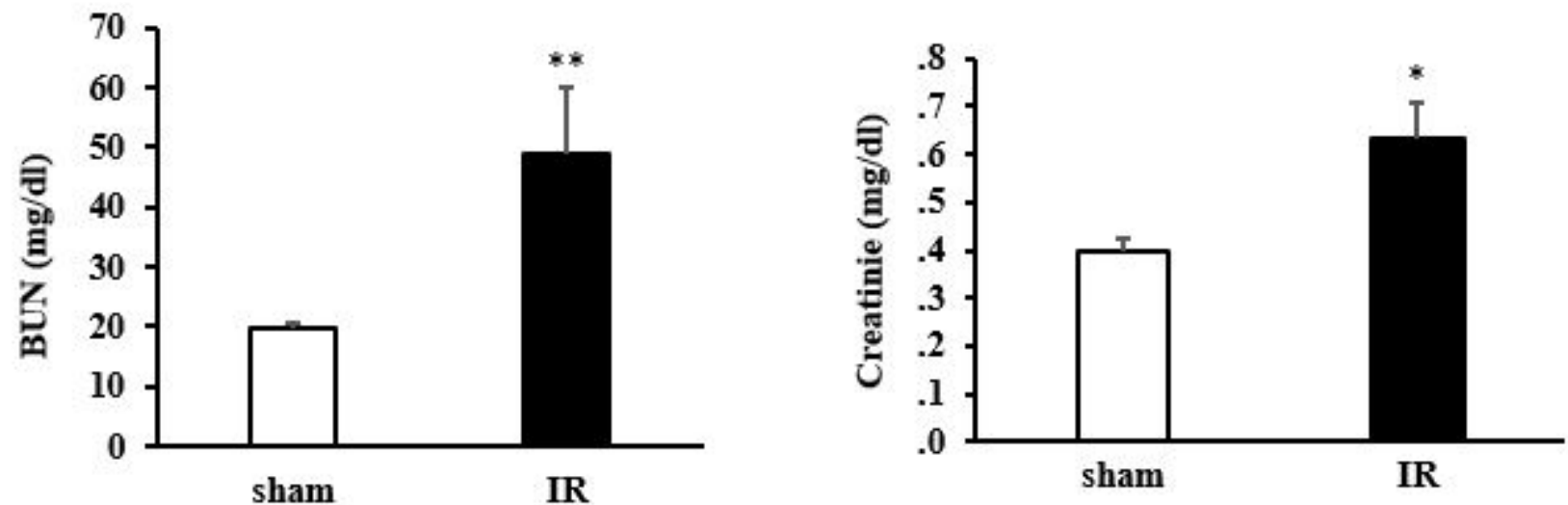

Fig.1. Renal functional parameters (blood urea nitrogen $[B U N]$ and creatinine concentration) in sham-operated control rats (sham) and acute kidney injury induced by ischemia-reperfusion injury (IR). Each bar represents the mean $\pm S E M(n=8)$. ${ }^{*} P<0.05$ and ${ }^{* *} P<0.01$ compared to sham-operated group.

$75 \%$ involvement of the cortex or outer medulla] and $4=$ severe damage $[>75 \%$ involvement of the cortex or outer medulla]) (Malek and Nematbakhsh, 2014).

\section{Gene expression analyses}

Tissue samples (ischemic kidney and hippocampus) were cut into $35-40 \mathrm{mg}$ pieces and were homogenized with RNX-Plus solution (Sinaclon, Iran) using an automated homogenizer (Precellys $\AA^{24}$; Bertin Technologies, France). Total RNA was then purified according to the manufacturer's protocol. For the elimination of genomic DNA from samples, RNAs were treated with RNase-free DNase I (Sinaclon, Iran). Subsequently, cDNA was synthesized with the cDNA Synthesis Kit (Yekta Tajhiz Azma, Iran) containing M-MLV reverse transcriptase, random hexamer primers, $5 \mathrm{X}$ first-strand buffer, RNasein and dNTP according to the protocol. For assessing gene expression, qRT-PCR was carried out on Miat and Actb (as a reference gene) genes with specific primers (Table 1) and RealQ Plus 2x Master Mix Green High ROX ${ }^{\mathrm{TM}}$ (Ampliqon, Denmark). The qRTPCR was applied for 40 cycles: stage1, an initial denaturation step at $95^{\circ} \mathrm{C}$ for $15 \mathrm{~min}$ and stage2, secondary denaturation at $95^{\circ} \mathrm{C}$ for $15 \mathrm{~s}$ and annealing/extension at $60^{\circ} \mathrm{C}$ for $1 \mathrm{~min}$. Data outcome from Miat gene expression was normalized with the expression of Actb of each sample. Calculation of relative gene expression was based on $2^{-\triangle \Delta C T}$ (Livak and Schmittgen, 2001).

\section{Statistical analyses}

All gene expression experiments were performed at least three times. Student's t-test was utilized to compare the mean expression of Miat between nonischemic (sham) and ischemic groups. The data were analyzed using GraphPad Prism software, version 5.01 (GraphPad Software Inc., San Diego, CA, US). All data were expressed as mean \pm SEM and $P$ values of $<0.05$ were considered statistically significant. The mean of the differences between groups was compared using the Student t-paired test and pathological damages scores between two independent groups that failed to pass a normality test or an equal variance test, were compared by Mann-Whitney test as a nonparametric test.

\section{Results}

\section{Biochemical and histological assessment}

To confirm renal damage and AKI model, serum blood urea nitrogen (BUN) and creatinine as well as 
A

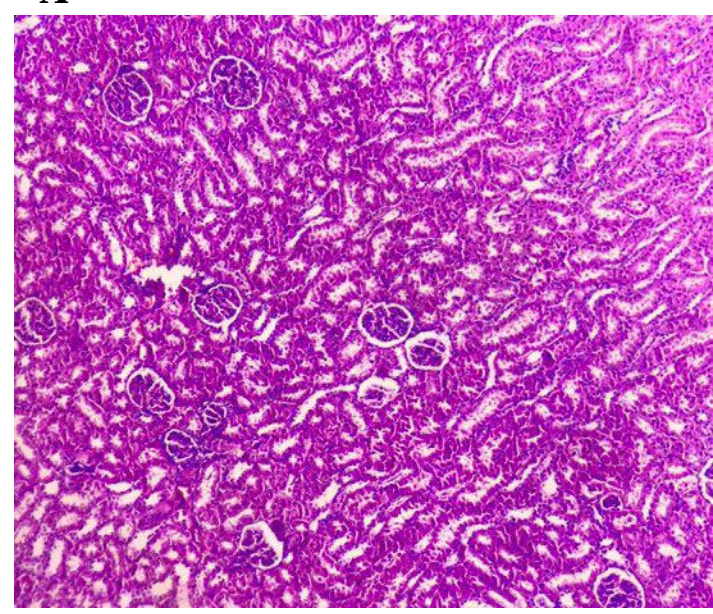

B

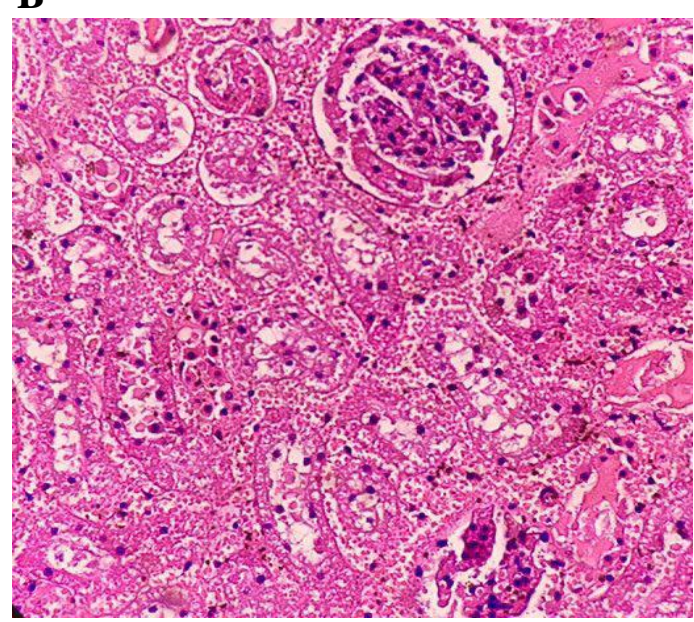

C

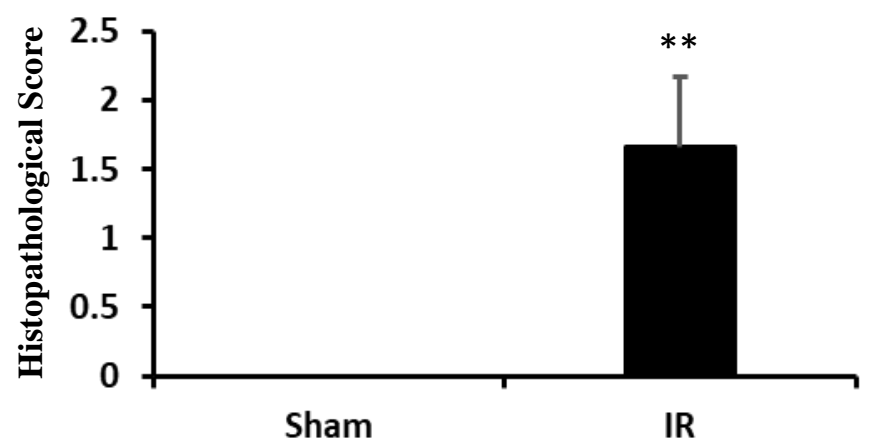

Fig.2. Kidney stained sections (hematoxylin and eosin; magnification $\times 200$ ) show normal structure of the glomeruli, interstitium and tubules in sham operated group (A). Arrows show dilatation of Bowman's space, tubular swelling and glomerulus degeneration affected in the renal ischemia-reperfusion (IR) group (B). Histopathological score in experimental groups indicates a significant tissue injury in IR compared to normal appearance (score $=0)$ of sham-operated animals $(C)$. ${ }^{* *} P<0.01$, bars represent mean \pm SEM $(n=8)$.

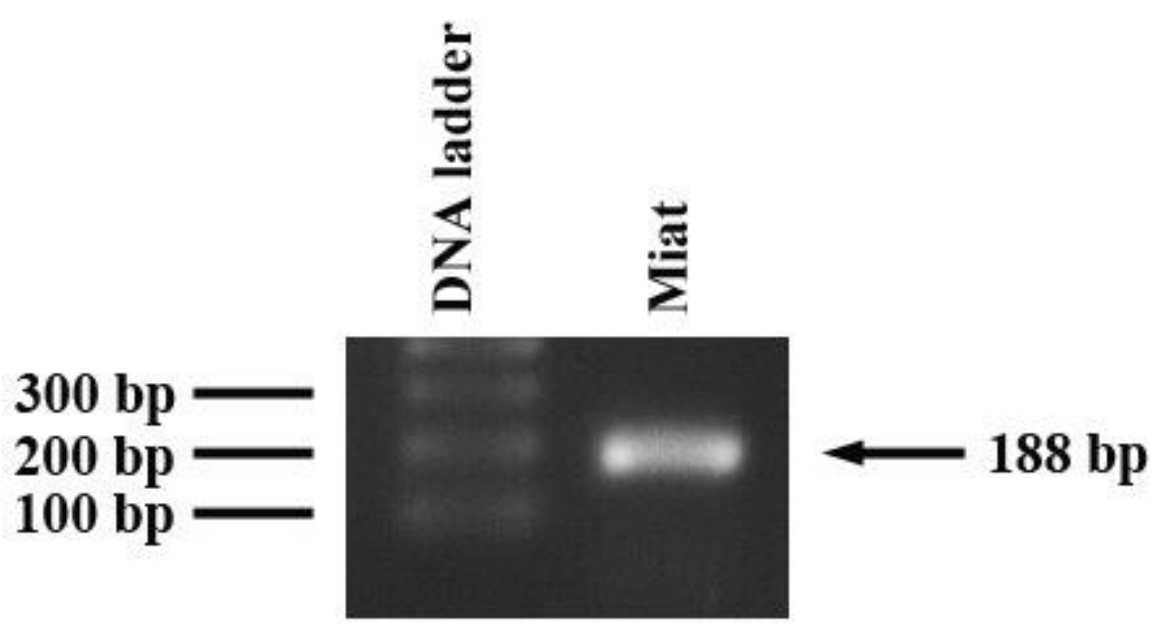

Fig.3. Electrophoresis of Miat PCR product on agarose gel. First lane represents the 100bp DNA ladder and the second lane represents the result of conventional RT-PCR performed on RNA extracted from a kidney tissue. PCR product on the second lane displayed a unique band with an anticipated size (188bp) for Miat transcript on the agarose gel. 
A

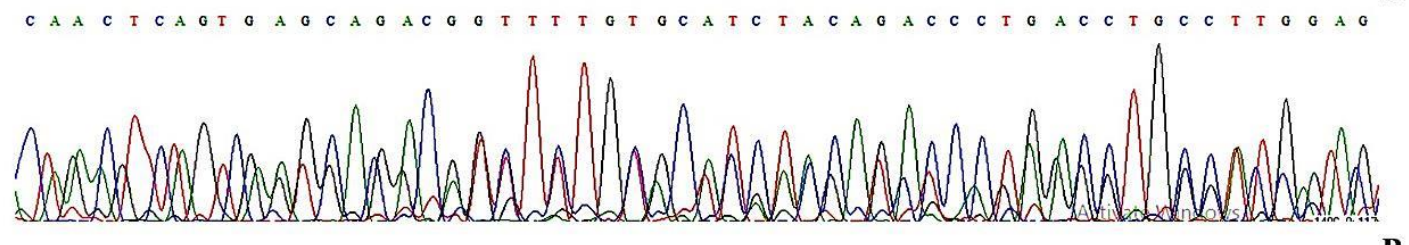

Rattus norvegicus myocardial infarction associated transcript (non-protein coding) (Miat), long non-coding RNA

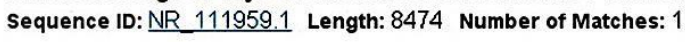

\begin{tabular}{|c|c|c|c|c|c|c|}
\hline $\begin{array}{l}\text { Score } \\
127 \text { bit }\end{array}$ & $s(140)$ & $\begin{array}{l}\text { Expect } \\
3 \mathrm{e}-28\end{array}$ & $\begin{array}{l}\text { Identities } \\
81 / 88(92 \%)\end{array}$ & $\begin{array}{l}\text { Gaps } \\
0 / 88(0 \%)\end{array}$ & $\begin{array}{l}\text { Strand } \\
\text { Plus/Plus }\end{array}$ & \\
\hline Query & 44 & \multirow{2}{*}{\multicolumn{4}{|c|}{ 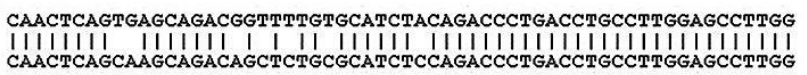 }} & 103 \\
\hline sbjet & 1349 & & & & & 1408 \\
\hline Query & 104 & \multirow{2}{*}{\multicolumn{2}{|c|}{ 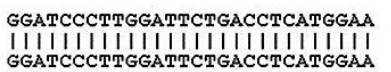 }} & & & \\
\hline Sbjet & 1409 & & & & & \\
\hline
\end{tabular}

Fig.4. Confirming the identity of Miat RT-PCR product using Sanger sequencing and BLAST against Rattus norvegicus genome. A) A part of a sequence electropherogram of the Miat PCR product; B) Comparison of sequence against Rattus norvegicus transcripts using the nucleotide BLAST (https://blast.ncbi.nlm.nih.gov/Blast.cgi) revealed the correct identity of the PCR product as Miat transcript.
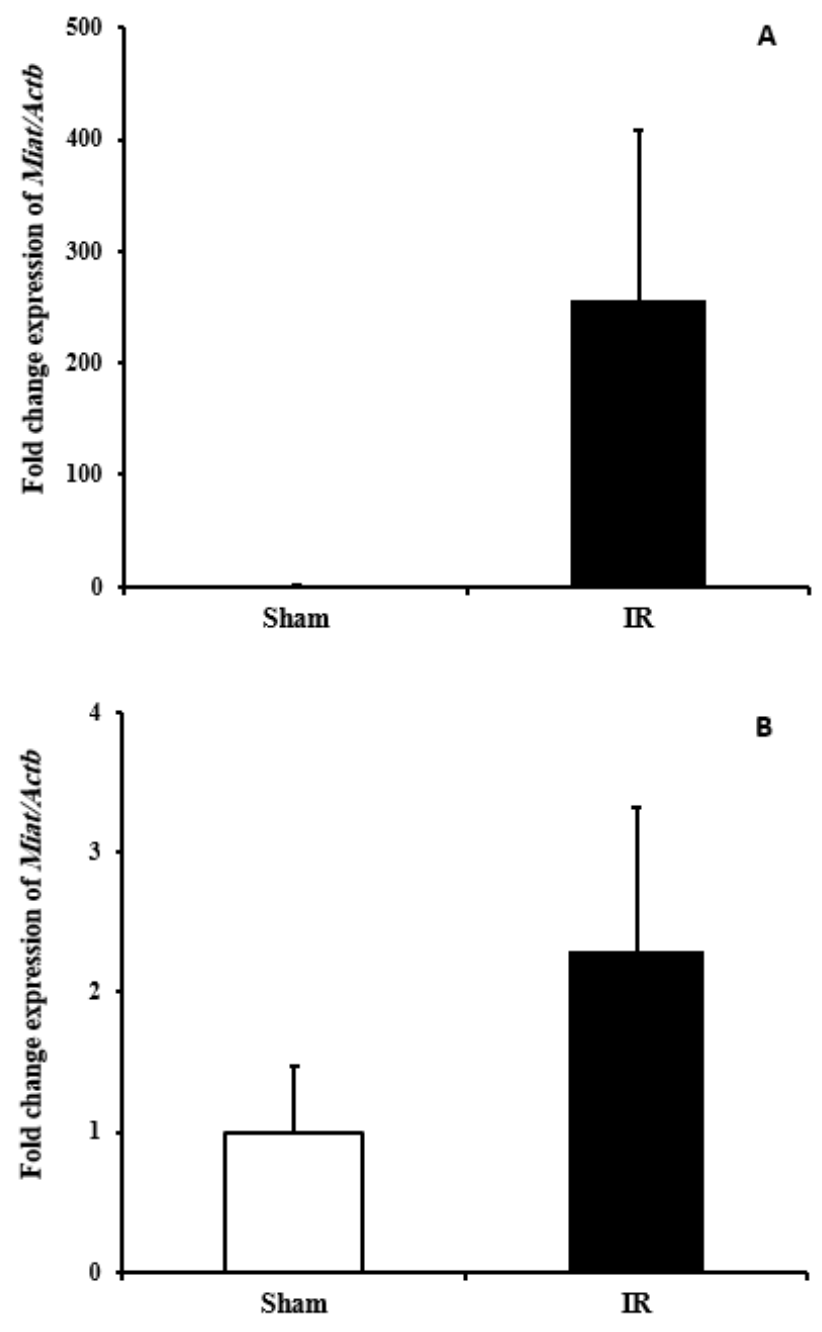

Fig.5. Relative expression of Miat in the kidney and hippocampus after the ischemia induction of the kidney using quantitative RT-PCR. Miat relative expression was determined in the kidney $(A)$ and hippocampus (B) tissues of rats' renal ischemia-reperfusion model. Miat gene expression in sham-operated rats was considered as calibrator (set as 1). Bars represent mean \pm SEM. IR: ischemic reperfusion group, sham: non-ischemic control group. 
histopathological examination of kidney tissue were measured. Renal functional parameters (BUN and creatinine) as well as histopathology scoring in animals that underwent renal ischemia reperfusion verified a significant increase in both creatinine and BUN levels and histopathology score, compared with sham-operated control rats (creatinine: $\mathrm{t}=2.91$, $P=0.021 ; \quad B U N: \quad \mathrm{t}=2.42, \quad P=0.003 ; \quad$ Fig. 1 and histopathological score: $P=0.007$ Fig. 2C). Histological examination showed tissue damage, necrosis with dilatation of Bowman's space, tubular swelling and glomerulus degeneration in ischemic reperfused-kidney compared to sham operated group (Figs. 2A and B, see histological score Fig. 2C). There was a statistically significant increase in histopathological score in ischemia/reperfusion $(1.67 \pm 0.5)$ versus sham group.

\section{Optimization of qRT-PCR reaction}

Specificity and optimized conditions for primers were firstly checked by conventional PCR and agarose gel electrophoresis. Results of gel electrophoresis displayed the specific band with expected amplicon size for both genes (Fig. 3). The specificity of Miat PCR amplicon was furthermore confirmed by Sanger sequencing (Fig. 4A). Blasting the sequence against Rattus norvegicus transcripts confirmed the identity of the Miat amplicon (Fig. 4B). Following conventional PCR optimization, quantitative PCR (qPCR) was performed and unique melting curves indicated a successful PCR amplification with a single specific amplicon (data not shown).

\section{Miat gene expression profile in the kidney and hippocampus}

Relative expression of Miat was measured in the rat kidney and hippocampus using qRT-PCR. The calculated expression values of ischemic and sham tissues were then compared between two groups to determine the expression of a sample relative to a calibrator (non-ischemic group). Ischemic kidney group showed a 256-fold increase in Miat expression relative to the sham group, although this increase was not statistically significant $(P=0.06$, Fig. $5 \mathrm{~A})$. The trend in Miat over-expression was the same in the hippocampus of ischemic group, in such a way that Miat showed a 2-fold increase in the ischemic group compared to non-ischemic one with a $P$ value which was 0.153 (Fig. 5B).

\section{Discussion}

Nowadays, IncRNAs have attracted lots of attentions in the scientific community because of their fundamentally important roles in biological processes and human diseases. Dysregulation of IncRNAs is associated with the development of various complex diseases including inflammatory diseases (Reddy et al., 2014; Lin et al., 2015; Mirza et al., 2015; Yang et al., 2017). AKI has to be considered a systemic inflammatory condition that may have substantial harmful effects on multiple extrarenal distant organs (Yap and Lee, 2012; Nongnuch et al., 2014; Rabb et al., 2016). Cellular abnormalities and inflammation with increased pyknotic neuronal cells in the brain, particularly in the hippocampus as a prime target has been demonstrated following AKI model (Liu et al., 2008). Recent studies also highlighted the regulatory role of IncRNAs in immune cell differentiation and immune system as well as inflammatory responses, especially in modulation of transcriptional control of inflammatory genes (Carpenter et al., 2013; Heward and Lindsay, 2014; llott et al., 2014; Puthanveetil et al., 2015; Zhou et al., 2016; Chen et al., 2017; Mathy and Chen, 2017). Although inflammation is a potential pathophysiology of acute renal failure, the role of IncRNAs in the pathogenesis of AKI and remote organ injury are still unclear. Uremic encephalopathy, an acquired toxic disorder, develops more in acute kidney injury than in chronic disease and is manifested with diverse cognitive symptoms and dementia in critically ill patients (Tsai et al., 2017). Because the hippocampus plays a major role in cognitive functions and is a prime region involved in $\mathrm{AKI}$, this study was conducted to evaluate the expression of IncRNA Miat in the hippocampus after ischemia/reperfusion induced AKI. Acute kidney injury was approved with a significantly increased histopathology scores and functional parameters of the kidney. Histological analysis of kidney sections at day 1 after renal ischemia reperfusion revealed significant tubular damage and Bowman's dilation with higher scores of renal histological lesions, which were not seen in sham control (Fig. 2). We identified a trend for IncRNA Miat up-regulation in the kidney after AKI. Even though this up-regulation was not statistically significant, but with a major trend we hypothesized that AKI could be associated with deregulation of IncRNA Miat in the kidney. 
Interestingly, this up-regulation was also accompanied by a trend towards increased expression of Miat in the hippocampus as well. The up-regulation of Miat in the hippocampus may be associated with behavioral alterations that include mental and cognitive deficits which are seen in AKI patients (Barry et al., 2014; Kao et al., 2017). Barry et al. (2014) demonstrated that IncRNA Miat is acutely regulated by neuronal activity and dysregulated in schizophrenia patient brains which may contribute to plasticity-related activity-dependent alternative splicing.

Hippocampus is a vulnerable brain region involved in uremic encephalopathy which is associated with deficits in a variety of cognitive and memory tasks in acute and chronic kidney diseases (Bugnicourt et al., 2013; Kovalčíková et al., 2018). As discussed earlier, the association between kidney and brain hippocampus has been identified by inflammation and cellular abnormalities in the hippocampus following AKI (Liu et al., 2008). Because of the involvement of IncRNAs in the immune system as critical regulators of inflammatory processes (Heward and Lindsay, 2014), it seems that up-regulation of Miat may play a role in the hippocampus inflammation. Nuclear factor-kB (NF-kB) represents a family of inducible transcription factors, which initiates induction of a large number of inflammatory genes during an immune responses (Liu et al., 2017). Recent evidence suggests that the Miat gene is a direct target of NF-KB to binding and promoting the expression of Miat under inflammatory states (Zhang et al., 2017). Miat also contributes to neuronal activity (Liao et al., 2016) and is widely expressed in the nervous system especially the CA1 region of the hippocampus that suggests a role in neuronal excitatory transmission. Up-regulation of Miat expression in nucleus accumbens of drug abusers may influence behavior with the regulation of the human genome (Albertson et al., 2006). Miat is included in a sub-category of IncRNAs that are involved in neural development and brain function and is expressed in differentiating neural progenitors and a subset of postmitotic neurons (Sone et al., 2007; Barry et al., 2014). Among all IncRNAs, Miat has critical functional roles that exhibits deregulation in some diseases including diabetic nephropathy (Zhou et al., 2015), ischemic stroke (Zhu et al., 2018), cardiomyopathy (Ishii et al., 2006) and Schizophrenia
(Barry et al., 2014). A growing body of evidence supports the contribution of microvasular disruption in potentially initiating blood brain barrier permeability and subsequently brain inflammation as well as initial tubular injury (Sutton et al., 2002; Sutton, 2009; Logsdon et al., 2015). It has been shown that IncRNA Miat has some regulatory effects on endothelial cell function due to its potential for neovascular disease treatment (Yan et al., 2015). Correlation of brain microvascular permeability and cerebral edema with $\mathrm{AKI}$ has been confirmed by pro-inflammatory chemokines in brain structures including hippocampus following renal ischemia reperfusion injury (Liu et al., 2008). From all of these evidences, it appears to be a potential relationship between the deregulation of the Miat expression in the kidney and hippocampus and $\mathrm{AKI}$, although more studies are needed to confirm the effect of this IncRNA on this regard.

\section{Conclusion}

The research that focuses on Miat is still in the early stage, and there is still uncertainty about its pathways involved in organ cross-link. This study provides a novel insight in correlation of this IncRNA with AKI and hippocampus and possibly future clinical target for ameliorating of $\mathrm{AKI}$ as well as molecular diagnosis of hippocampal involvement as a remote organ complication.

\section{Acknowledgments}

The present study was financially supported by Isfahan University of Medical Sciences (grant number 195068 to M.M).

\section{Conflict of interest}

The authors declare no conflict of interest.

\section{References}

Albertson DN, Schmidt CJ, Kapatos G, Bannon MJ. Distinctive profiles of gene expression in the human nucleus accumbens associated with cocaine and heroin abuse. Neuropsychopharmacology 2006; 31: 2304-12. DOI: 10.1038/sj.npp.1301089.

Barry G, Briggs JA, Vanichkina DP, Poth EM, Beveridge NJ, Ratnu VS, et al. The long non-coding RNA Gomafu is acutely regulated in response to neuronal activation and involved in schizophrenia-associated alternative splicing. Mol Psychiatry 2014; 19: 486-94. DOI: 10.1038/mp.2013.45

Blackshaw S, Harpavat S, Trimarchi J, Cai L, Huang H, 
Kuo WP, et al. Genomic analysis of mouse retinal development. PLoS Biol 2004; 2: E247. DOI: 10.1371/journal.pbio.0020247

Bugnicourt JM, Godefroy O, Chillon JM, Choukroun G, Massy ZA. Cognitive disorders and dementia in CKD: the neglected kidney-brain axis. J Am Soc Nephrol 2013; 24: 353-63. DOI: 10.1681/ASN.2012050536

Burn DJ, Bates D. Neurology and the kidney. J Neurol Neurosurg Psychiatry 1998; 65: 810-21. DOI: 10.1136/ jnnp.65.6.810

Carpenter S, Aiello D, Atianand MK, Ricci EP, Gandhi P, Hall LL, et al. A long noncoding RNA mediates both activation and repression of immune response genes. Science 2013; 341: 789-92. DOI: 10.1126/ science.1240925

Chen YG, Satpathy AT, Chang HY. Gene regulation in the immune system by long noncoding RNAs. Nat Immunol 2017; 18: 962-972. DOI: 10.1038/ni.3771

Chou AH, Lee CM, Chen CY, Liou JT, Liu FC, Chen YL, et al. Hippocampal transcriptional dysregulation after renal ischemia and reperfusion. Brain Res 2014; 1582: 197210. DOI: 0.1016/j.brainres.2014.07.030

De Deyn PP, Saxena VK, Abts H, Borggreve F, D'Hooge R, Marescau B, et al. Clinical and pathophysiological aspects of neurological complications in renal failure. Acta Neurol Belg 1992; 92: 191-206.

Doi K, Rabb H. Impact of acute kidney injury on distant organ function: recent findings and potential therapeutic targets. Kidney Int 2016; 89: 555-64. DOI: 10.1016/ j.kint.2015.11.019

Fenoglio C, Ridolfi E, Galimberti D, Scarpini E. An emerging role for long non-coding RNA dysregulation in neurological disorders. Int J Mol Sci 2013; 14: $20427-$ 42. DOI: 10.3390/ijms141020427

Heward JA, Lindsay MA. Long non-coding RNAs in the regulation of the immune response. Trends Immunol 2014; 35: 408-19. DOI: 10.1016/j.it.2014.07.005

Ilott NE, Heward JA, Roux B, Tsitsiou E, Fenwick PS, Lenzi $L$, et al. Long non-coding RNAs and enhancer RNAs regulate the lipopolysaccharide-induced inflammatory response in human monocytes. Nat commun 2014; 5: 3979. DOI: $10.1038 /$ ncomms7814

Ishii N, Ozaki K, Sato H, Mizuno H, Saito S, Takahashi A, et al. Identification of a novel non-coding RNA, MIAT, that confers risk of myocardial infarction. J Hum Genet 2006; 51: 1087-99. DOI: 10.1007/s10038-006-0070-9

Kao CC, Wu CH, Lai CF, Huang TM, Chen HH, Wu VC, et al. Long-term risk of dementia following acute kidney injury: a population-based study. Ci Ji Yi Xue Za Zhi 2017; 29: 201-207. DOI: 10.4103/tcmj.tcmj_40_17

Kovalčíková A, Gyurászová $M$, Vavrincová-Yaghi D, Vavrinec $\mathrm{P}$, Tóthová L', Boor $\mathrm{P}$, et al. Oxidative stress in the brain caused by acute kidney injury. Metab Brain Dis 2018; 33: 961-967. DOI: 10.1007/s11011-018-02048

Liao J, He Q, Li M, Chen Y, Liu Y, Wang J. LncRNA MIAT: myocardial infarction associated and more. Gene 2016; 578: 158-61. DOI: 10.1016/j.gene.2015.12.032

Lin J, Zhang X, Xue C, Zhang H, Shashaty MG, Gosai SJ, et al. The long noncoding RNA landscape in hypoxic and inflammatory renal epithelial injury. Am $\mathrm{J}$ of Physiol Renal Physiol 2015; 309: F901-F13. DOI: 10.1152/ajprenal.00290.2015

Liu M, Liang Y, Chigurupati S, Lathia JD, Pletnikov M, Sun $Z$, et al. Acute kidney injury leads to inflammation and functional changes in the brain. J Am Soc Nephrol 2008; 19: 1360-70. DOI: 10.1681/ASN.2007080901

Liu T, Zhang L, Joo D, Sun SC. NF-kB signaling in inflammation. Signal Transduct Target Ther 2017; 2: 17023. DOI: $10.1038 /$ sigtrans.2017.23

Livak KJ, Schmittgen TD. Analysis of relative gene expression data using real-time quantitative PCR and the 2(-Delta Delta C(T)) Method. Methods 2001; 25: 402-8. DOI: 10.1006/meth.2001.1262

Logsdon AF, Lucke-Wold BP, Turner RC, Huber JD, Rosen $\mathrm{CL}$, Simpkins JW. Role of microvascular disruption in brain damage from traumatic brain injury. Compr Physiol 2015; 5: 1147-60. DOI: 10.1002/cphy.c140057

Lorenzen JM, Thum T. Long noncoding RNAs in kidney and cardiovascular diseases. Nat Rev Nephrol 2016; 12: 360-73. DOI: 10.1038/nrneph.2016.51

Lu R, Kiernan MC, Murray A, Rosner MH, Ronco C. Kidney-brain crosstalk in the acute and chronic setting. Nat Rev Nephrol 2015; 11: 707-19. DOI: 10.1038/nrneph.2015.131

Malek M, Nematbakhsh M. The preventive effects of diminazene aceturate in renal ischemia/reperfusion injury in male and female rats. Adv Prev Med 2014; 2014: 740647. DOI: 10.1155/2014/740647

Mathy NW, Chen X-M. Long non-coding RNAs (IncRNAs) and their transcriptional control of inflammatory responses. J Biol Chem 2017; 292: 12375-12382. DOI: 10.1074/jbc.R116.760884

Mirza $\mathrm{AH}$, Berthelsen $\mathrm{CH}$, Seemann SE, Pan $\mathrm{X}$, Frederiksen KS, Vilien $\mathrm{M}$, et al. Transcriptomic landscape of IncRNAs in inflammatory bowel disease. Genome med 2015; 7: 39. DOI: 10.1186/s13073-0150162-2

Nasrollahzadeh-Khakiani M, Emadi-Baygi M, Nikpour P. Augmented expression levels of IncRNAs ecCEBPA and UCA1 in gastric cancer tissues and their clinical significance. Iran J Basic Med Sci 2017a; 20: 1149-58. DOI: 10.22038/IJBMS.2017.9448

Nasrollahzadeh-Khakiani M, Emadi-Baygi M, Schulz WA, Nikpour $\mathrm{P}$. Long noncoding RNAs in gastric cancer carcinogenesis and metastasis. Brief Funct Genomics 2017b; 16: 129-45. doi: 10.1093/bfgp/elw011

Niland CN, Merry CR, Khalil AM. Emerging roles for long non-coding RNAs in cancer and neurological disorders. Front Genet 2012; 3: 25. DOI: 10.3389/ fgene.2012.00025

Nongnuch A, Panorchan K, Davenport A. Brain-kidney crosstalk. Critical care 2014; 18: 225 . DOI: 10.1186/cc13907

Ohnishi Y, Tanaka T, Yamada R, Suematsu K, Minami M, Fujii K, et al. Identification of 187 single nucleotide polymorphisms (SNPs) among 41 candidate genes for ischemic heart disease in the Japanese population. 
Hum Genet 2000; 106: 288-92. DOI: 10.1007/ s004390051039

Puthanveetil P, Chen S, Feng B, Gautam A, Chakrabarti S. Long non-coding RNA MALAT1 regulates hyperglycaemia induced inflammatory process in the endothelial cells. J Cell Mol Med 2015; 19: 1418-25. DOI: $10.1111 / \mathrm{jcmm} .12576$

Rabb H, Griffin MD, McKay DB, Swaminathan S, Pickkers $\mathrm{P}$, Rosner $\mathrm{MH}$, et al. Inflammation in $\mathrm{AKI}$ : current understanding, key questions, and knowledge gaps. J Am Soc Nephrol 2016; 27: 371-9. DOI: 10.1681/ASN.2015030261

Reddy MA, Chen Z, Park JT, Wang M, Lanting L, Zhang Q, et al. Regulation of inflammatory phenotype in macrophages by a diabetes-induced long noncoding RNA. Diabetes 2014; 63: 4249-61. DOI: 10.2337/db140298

Salvadori M, Rosso G, Bertoni E. Update on ischemiareperfusion injury in kidney transplantation: pathogenesis and treatment. World J Transplant 2015; 5: 52-67. DOI: 10.5500/wjt.v5.i2.52

Shiao CC, Wu PC, Huang TM, Lai TS, Yang WS, Wu CH, et al. Long-term remote organ consequences following acute kidney injury. Crit Care 2015; 19: 438. DOI: 10.1186/s13054-015-1149-5

Sone M, Hayashi T, Tarui H, Agata K, Takeichi M, Nakagawa S. The mRNA-like noncoding RNA Gomafu constitutes a novel nuclear domain in a subset of neurons. J Cell Sci 2007; 120: 2498-506. DOI: $10.1242 / j \mathrm{jcs} .009357$

Sun $\mathrm{C}$, Huang $\mathrm{L}$, Li Z, Leng $\mathrm{K}, \mathrm{Xu} \mathrm{Y}$, Jiang $\mathrm{X}$, et al. Long non-coding RNA MIAT in development and disease: a new player in an old game. J Biomed Sci 2018; 25: 23. DOI: 10.1186/s12929-018-0427-3

Sutton TA. Alteration of microvascular permeability in acute kidney injury. Microvasc Res 2009; 77: 4-7. DOI: 10.1016/j.mvr.2008.09.004

Sutton TA, Fisher CJ, Molitoris BA. Microvascular endothelial injury and dysfunction during ischemic acute renal failure. Kidney Int 2002; 62: 1539-49. DOI: 10.1046/j.1523-1755.2002.00631.x

Tsai $\mathrm{HH}$, Yen RF, Lin CL, Kao CH. Increased risk of dementia in patients hospitalized with acute kidney injury: A nationwide population-based cohort study. PloS one 2017; 12: e0171671. DOI: 10.1371/ journal.pone. 0171671

Yan B, Yao J, Liu JY, Li XM, Wang XQ, Li YJ, et al. IncRNA-MIAT regulates microvascular dysfunction by functioning as a competing endogenous RNA. Circ Res 2015; 116: 1143-56. DOI: 10.1161/CIRCRESAHA. 116.305510

Yang $\mathrm{H}$, Liang $\mathrm{N}$, Wang $\mathrm{M}$, Fei $\mathrm{Y}$, Sun J, Li Z, et al. Long noncoding RNA MALAT-1 is a novel inflammatory regulator in human systemic lupus erythematosus. Oncotarget 2017; 8: 77400. DOI: 10.18632/ oncotarget.20490

Yap SC, Lee HT. Acute kidney injury and extrarenal organ dysfunction: new concepts and experimental evidence. Anesthesiology 2012; 116: 1139-48. DOI: 10.1097/ALN.0b013e31824f951b

Zhang J, Chen M, Chen J, Lin S, Cai D, Chen C, et al. Long non-coding RNA MIAT acts as a biomarker in diabetic retinopathy by absorbing miR-29b and regulating cell apoptosis. Biosci Rep 2017; 37: BSR20170036. DOI: 10.1042/BSR20170036

Zhou L, Xu DY, Sha WG, Shen L, Lu GY, Yin X. Long noncoding MIAT mediates high glucose-induced renal tubular epithelial injury. Biochem Biophys Res Commun 2015; 468: 726-32. DOI: 10.1016/j.bbrc.2015.11.023

Zhou X, Han X, Wittfeldt A, Sun J, Liu C, Wang X, et al. Long non-coding RNA ANRIL regulates inflammatory responses as a novel component of NF-KB pathway. RNA Biol 2016; 13: 98-108. DOI: 10.1080/15476286. 2015.1122164

Zhu M, Li N, Luo P, Jing W, Wen X, Liang C, et al. Peripheral blood leukocyte expression of IncRNA MIAT and its diagnostic and prognostic value in ischemic stroke. J Stroke Cerebrovasc Dis 2018; 27: 326-337. DOI: 10.1016/j.jstrokecerebrovasdis.2017.09.009 